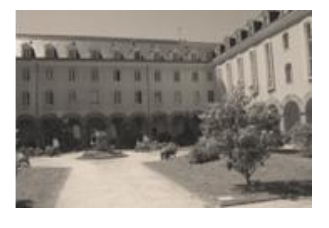

\title{
A SIMPLE MICROFOUNDATION FOR THE UTILIZATION OF FRAGMENTATION INDEXES TO MEASURE THE PERFORMANCE OF A TEAM
}

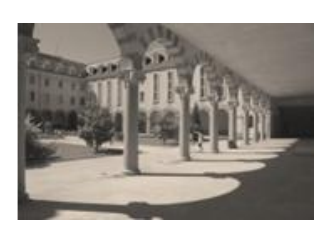

Yvon Rocaboy

University of Rennes I, CREM-CNRS

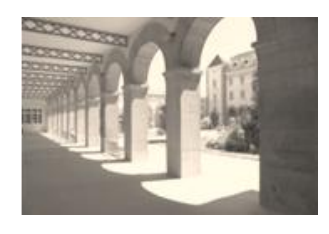

Benoît Le Maux

University of Rennes I, CREM-CNRS

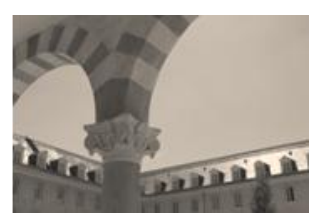

\section{Condorcet Center for Political ECONOMy} UNIVERSITY OF RENNES 1 - CREM - www.condorcet-center.fr 


\title{
A simple microfoundation for the utilization of fragmentation indexes to measure the performance of a team
}

\author{
Benoît LE MAUX \\ University of Rennes 1 and CREM-CNRS \\ Yvon ROCABOY* \\ University of Rennes 1 and CREM-CNRS
}

\begin{abstract}
We propose a simple non-cooperative game model where two fragmented teams compete to increase their performance. The theoretical framework is based on the theory of conflict. We show that depending on the value of a parameter in the model, the power of the competing teams may be expressed as a function of well-known fragmentation indexes: the Herfindhal-Hirschman index, the Laakso-Taagepera index, the Best shot index and the Weakest-link index.
\end{abstract}

JEL-Classification: D70, D71, D72, D74

Keywords: Contest success function, Fragmentation, Herfindhal-Hirschman index, Laakso-Taagepera index, Best shot index, Weakest-link index

${ }^{*}$ Corresponding author: Yvon Rocaboy, University of Rennes I, 7 Place Hoche, 35065 Rennes Cedex, France; E-mail: yvon.rocaboy@univ-rennes1.fr; Tel: +33223233546. 


\section{Introduction}

There is a large body of economic literature related to measuring the performance of a team. It is often argued that team's performance depends, among other things, on team's fragmentation. The effect of fragmentation on team's performance may be of different kinds. For instance, a political coalition composed of several parties may be more or less powerful depending on the fragmentation of the coalition. The intuition is that strategic interactions among members of the same coalition may lead to free-riding and that the greater the fragmentation of the coalition, the less the participation of parties in the coalition (e.g., Padovano and Venturi, 2001, Schalteger and Feld, 2009, and Le Maux et al, 2011). Likewise, the performance of sport or labor teams may also be linked to the concentration of salaries. Two reasons can be advanced to justify this link. First, due to cohesiveness issues, wage disparities may have a negative impact on team performance. This is the fairness hypothesis raised by Akerlof and Yellen (1990) and formalized by Levine (1991). On the other hand, Lazear and Rosen (1981) stress the positive impact of wage inequalities on workers' incentives to exert effort. These two competing hypotheses have been investigated empirically in several studies with controversial results (e.g., Depken, 2000, Jane et al, 2009, Jane, 2010). In the same vein, the performance of a military alliance depends not only on the overall resources of the alliance but also on the allies' contribution structure. At the limit only the highest contribution matters, this is the best shot rule or, conversely, only the smallest contribution is of importance, this is the weakest-link rule (see for instance Hirschleifer, 1983, Sandler and Hartley, 2001, Dutheil de la Rochère et al, 2011).

In the empirical literature fragmentation has often been aproximated by well-known fragmentation indexes such as (1) the Herfindhal-Hirschman index, (2) the Laakso-Taagepera index, (3) the Best shot index and (4) the Weakest-link index. To the best of our knowledge, no papers propose a microeconomic foundation for the utilisation of those fragmentation 
indexes to measure the performance of a team. This is what we do in the present paper. The theoretical framework is based on the theory of conflict in which contest is modeled thanks to contest success functions. Section 2 presents the theoretical framework. Section 3 shows that depending on the value of the cost parameter of the model, the power or performance of the team may be expressed as a function of one of these four fragmentation indexes. Section 4 conludes.

\section{Theoretical framework}

Consider a contest where two teams, labeled Team $A$ and Team $B$, have ressources denoted $r^{A}$ and $r^{B}$. A part of the team's resources can be dedicated to the team's production. This part may be considered as efforts exerted to increase the team's performance. Let us denote $e^{A}<r^{A}$ (respectively $e^{B}<r^{B}$ ) the effort level of Team $A$ (respectively Team $B$ ). We define the performance of each team to be:

$$
\pi^{A}\left(e^{A}, e^{B}\right)=\frac{e^{A}}{e^{A}+e^{B}} \quad \text { and } \quad \pi^{B}\left(e^{A}, e^{B}\right)=1-\pi^{A}\left(e^{A}, e^{B}\right)
$$

where $\pi^{A}\left(e^{A}, e^{B}\right)$ and $\pi^{B}\left(e^{A}, e^{B}\right)$ are contest success functions as in Tullock (1980) and Skaperdas (1996).

Each team is respectively composed of $n^{A}$ and $n^{B}$ groups. Each group has to choose the level of resources it will devote to the effort level of the team. More specifically, the resources of Group $p$ in Team $A, p=1 \ldots n^{A}$, is denoted $r_{p}^{A}$. Similarly, the maximum level of resources Group $p$ in Team $B$ can mobilize is denoted $r_{p}^{B}, p=1 \ldots n^{B}$. Let $e_{p}^{A} \leq r_{p}^{A}$ (respectively $e_{p}^{B} \leq r_{p}^{B}$ ) accounts for the efforts made by Group $p$ of Team $A$ (respectively of Team $B$ ). It can also be considered as the level of Group $p$ 's resources dedicated to the team production. We have $\sum_{p=1}^{n^{A}} e_{p}^{A}=e^{A}$ and $\sum_{p=1}^{n^{B}} e_{p}^{B}=e^{B}$.

The groups within each team are assumed to behave non-cooperatively. Group $p$ in 
Team $A$ chooses its effort level $e_{p}^{A}$ so as to maximize its payoff. This payoff is defined as the difference between its benefit in terms of performance, $\pi^{A}$, and the cost of the effort $e_{p}^{A} / r_{p}^{A}$, i.e., the share of Group $p$ 's resources devoted to the team production:

$$
U_{p}^{A}\left(e_{p}^{A}\right)=\frac{e^{A}}{e^{A}+e^{B}}-\left(\frac{e_{p}^{A}}{r_{p}^{A}}\right)^{\lambda}, \quad \quad p=1 \ldots n^{A}
$$

where $\lambda \geq \mu$ and $\mu \in] 0,1[$, to ensure that second order conditions are met. The effort level of Group $p$ in Team $A$ must satisfy the following first-order conditions:

$$
\frac{\partial U_{p}^{A}}{\partial e_{p}^{A}}=\frac{e^{B}}{\left(e^{A}+e^{B}\right)^{2}}-\frac{\lambda}{r_{p}^{A}}\left(\frac{e_{p}^{A}}{r_{p}^{A}}\right)^{\lambda-1}=0, \quad p=1 \ldots n^{A} .
$$

Rewriting the first-order conditions gives $e_{p}^{A}=\left(r_{p}^{A}\right)^{\frac{\lambda}{\lambda-1}}\left(\frac{e^{B}}{\lambda\left(e^{A}+e^{B}\right)^{2}}\right)^{\frac{1}{\lambda-1}}, p=1 \ldots n^{A}$. Since $e^{A}=\sum_{p=1}^{n^{A}} e_{p}^{A}$, we have

$$
e^{A}=\sum_{p=1}^{n^{A}}\left(r_{p}^{A}\right)^{\frac{\lambda}{\lambda-1}}\left(\frac{e^{B}}{\lambda\left(e^{A}+e^{B}\right)^{2}}\right)^{\frac{1}{\lambda-1}}
$$

which implicitly defines the optimal response of Team $A$ in terms of efforts to any effort level chosen by Team $B$. By symmetry, if the payoff of Group $p$ in Team $B$ is given by $U_{p}^{B}\left(e^{B}\right)=\frac{e^{B}}{e^{A}+e^{B}}-\left(\frac{e^{B}}{r_{p}^{A}}\right)^{\lambda}$, we find that

$$
e^{B}=\sum_{p=1}^{n^{B}}\left(r_{p}^{B}\right)^{\frac{\lambda}{\lambda-1}}\left(\frac{e^{A}}{\lambda\left(e^{A}+e^{B}\right)^{2}}\right)^{\frac{1}{\lambda-1}}
$$

which implicitly defines the reaction function of Team $B$. It follows from equations (4) and (5) that

$$
\frac{e^{A}}{e^{B}}=\left(\frac{X^{A}}{X^{B}}\right)^{\frac{\lambda-1}{\lambda}}
$$


Table 1. Team performance $\pi^{A *}$ and fragmentation indexes

\begin{tabular}{ccccc}
\hline \hline$\lambda \rightarrow+\infty$ & $\lambda=2$ & $\lambda=2$ & $\lambda \rightarrow 1^{+}$ & $\lambda \rightarrow 1^{-}$ \\
\hline Share of & Herfindahl- & Laakso-Taagepera & Best shot & Weakest link \\
resources & Hirschman & effective number & index & index \\
& index & of parties & & \\
$\frac{r^{A}}{r^{A}+r^{B}}$ & $\frac{r^{A} \sqrt{H H I^{A}}}{r^{A} \sqrt{H H I^{A}+r^{B} \sqrt{H H I^{B}}}}$ & $\frac{r^{A} \sqrt{E N P^{B}}}{r^{A} \sqrt{E N P^{B}}+r^{B} \sqrt{E N P^{A}}}$ & $\frac{r^{A} \alpha_{\max }^{A}}{r^{A} \alpha_{\max }^{A}+r^{B} \alpha_{\max }^{B}}$ & $\frac{r^{A} \alpha_{\min }^{A}}{r^{A} \alpha_{\min }^{A} r^{B} \alpha_{\min }^{B}}$ \\
\hline \hline
\end{tabular}

where

$$
X^{K}=\sum_{p=1}^{n^{K}}\left(r_{p}^{K}\right)^{\frac{\lambda}{\lambda-1}}=\left(r^{K}\right)^{\frac{\lambda}{\lambda-1}} \sum_{p=1}^{n^{K}}\left(\alpha_{p}^{K}\right)^{\frac{\lambda}{\lambda-1}}, K=A, B
$$

and $\alpha_{p}^{K}=\frac{r_{p}^{K}}{r^{K}}$ denotes the share of Group $p$ 's resources in Team $K$ 's total resources.

Using equation (6) with equations (4) and (5) yields the Nash equilibrium effort levels of Team $A$ and Team $B$ :

$$
e^{K *}=\left(X^{K}\right)^{\frac{\lambda-1}{\lambda}}\left(\frac{\left(X^{A}\right)^{\frac{\lambda-1}{\lambda}}\left(X^{B}\right)^{\frac{\lambda-1}{\lambda}}}{\lambda\left(\left(X^{A}\right)^{\frac{\lambda-1}{\lambda}}+\left(X^{B}\right)^{\frac{\lambda-1}{\lambda}}\right)^{2}}\right)^{\frac{1}{\lambda}}, K=A, B
$$

The equilibrium effort of a team depends on its relative total resources and its relative fragmentation. By using equation (8) with equations (1) and (7), we directly find the equilibrium value of Team $A$ 's performance:

$$
\pi^{A *}=\frac{r^{A}\left(\sum_{p=1}^{n^{A}}\left(\alpha_{p}^{A}\right)^{\frac{\lambda}{\lambda-1}}\right)^{\frac{\lambda-1}{\lambda}}}{r^{A}\left(\sum_{p=1}^{n^{A}}\left(\alpha_{p}^{A}\right)^{\frac{\lambda}{\lambda-1}}\right)^{\frac{\lambda-1}{\lambda}}+r^{B}\left(\sum_{p=1}^{n^{B}}\left(\alpha_{p}^{B}\right)^{\frac{\lambda}{\lambda-1}}\right)^{\frac{\lambda-1}{\lambda}}}
$$




\section{Team performance and fragmentation indexes}

The impact of the resources distribution i.e., how the team is fragmented, on the team's performance depends on the value of cost parameter $\lambda$. We will focus on a few values of $\lambda$ which make appear well-known fragmentation indexes (see Table 1).

If $\lambda \rightarrow \infty$, the cost of efforts of group $p$ in Team $A$ tends to zero because $\left(\frac{e_{p}^{A}}{r_{p}^{A}}\right)<1$ (see Equation 2). The equilibrium performance of Team $A$ is only defined by the share of team $A$ 's resources in the teams' total resources. Fragmentation here does not matter. If $\lambda$ takes a finite value, the team's relative fragmentation has an impact on the team's equilibrium performance.

If $\lambda=2$ team $A$ 's performance is increasing with its Herfindahl-Hirschman index: $\mathrm{HHI}^{A}=\sum_{p=1}^{n^{A}}\left(\alpha_{p}^{A}\right)^{2}$. Following the usual properties of this index, the less fragmented Team $A$, the higher its performance. This index has often been used to assess the impact of wage concentration on the performance of sports teams. For the same value of $\lambda$ the performance of $K$ may also be expressed as a decreasing function of its effective number of groups: $\operatorname{ENP}^{A}=\frac{1}{\sum_{p=1}^{n^{A}}\left(\alpha_{p}^{A}\right)^{2}}$ as defined by Laakso and Taagepera (1979). The ENP index is widely used among the political scientists to measure the number of "relevant" parties in a political system and to make comparison of the political power of governments across countries.

If $\lambda \rightarrow 1^{+}$, the team's performance increases with the size of the biggest group of the team in terms of resources share, $\alpha_{\max }^{A}=\max \left(\alpha_{1}^{A}, \ldots, \alpha_{n^{A}}^{A}\right)$. This is known as the best shot rule in the economics of conflict literature. Only the contribution of the biggest group matters (see Appendix A). Returning to Equation 2, since $\lambda>1$, one can easily show that these indexes are coherent with the assumption that the marginal cost of effort is increasing.

If $\lambda=\rightarrow 1^{-}$, the team's performance increases with the resources of the smallest group, $\alpha_{\min }^{A}=\min \left(\alpha_{1}^{A}, \ldots, \alpha_{n^{A}}^{A}\right)$. In the economics of conflict literature this assumption is known as the weakest link rule (see Appendix B). Since $\lambda \in[\mu, 1[$, this index is coherent with the assumption that the marginal cost of efforts is decreasing. 
Table 2. Examples of application

\begin{tabular}{|c|c|c|c|c|c|}
\hline Field & $\begin{array}{l}\text { Team } K \\
K=A, B\end{array}$ & $\begin{array}{l}\text { Number } \\
n^{K}\end{array}$ & $\begin{array}{l}\text { Ressources } \\
r_{p}^{K}\end{array}$ & $\begin{array}{l}\text { Effort } \\
e_{p}^{K}\end{array}$ & $\begin{array}{l}\text { Performance } \\
\pi^{K}\end{array}$ \\
\hline Political economy & $\begin{array}{l}\text { Left-wing and } \\
\text { Right-wing } \\
\text { coalitions }\end{array}$ & $\begin{array}{l}\text { Number of po- } \\
\text { litical parties in } \\
\text { coalition } K\end{array}$ & $\begin{array}{l}\text { Size of party } p \\
\text { (e.g., number of } \\
\text { politicians, number } \\
\text { of seats) }\end{array}$ & $\begin{array}{l}\text { Number of party } \\
p \text { 's members who } \\
\text { actively defend and } \\
\text { promote the ideas } \\
\text { of coalition } K \text { in the } \\
\text { debate }\end{array}$ & $\begin{array}{l}\text { Probability of win- } \\
\text { ning the elections } \\
\text { or probability of in- } \\
\text { fluencing the policy } \\
\text { choices }\end{array}$ \\
\hline Economics of conflict & $\begin{array}{l}\text { Two alliances } \\
\text { of countries }\end{array}$ & $\begin{array}{l}\text { Number of coun- } \\
\text { tries in alliance } K\end{array}$ & $\begin{array}{l}\text { Size of country } p \text { 's } \\
\text { army }\end{array}$ & $\begin{array}{l}\text { Contribution of } \\
\text { country } p \text { to the } \\
\text { alliance's force }\end{array}$ & $\begin{array}{l}\text { Probability of an } \\
\text { alliance's victory in } \\
\text { a conflict }\end{array}$ \\
\hline $\begin{array}{l}\text { Sport or labor eco- } \\
\text { nomics }\end{array}$ & $\begin{array}{l}\text { Two sport or } \\
\text { labor teams }\end{array}$ & $\begin{array}{l}\text { Number of play- } \\
\text { ers or workers in } \\
\text { team } K\end{array}$ & $\begin{array}{l}\text { Wage of player or } \\
\text { worker } p\end{array}$ & $\begin{array}{l}\text { Effort of player } p \\
\text { to win the match } \\
\text { or of worker } p \text { to } \\
\text { accomplish a task }\end{array}$ & $\begin{array}{l}\text { Probability to win } \\
\text { the match or to } \\
\text { accomplish a task } \\
\text { successfully }\end{array}$ \\
\hline
\end{tabular}

\section{Conclusion}

In the present paper we have proposed a microfounded performance measure that can be expressed as a function of well-known fragmentation indexes by giving specific values to the cost parameter of the model. Our formalism could easily be applied to issues in political economy, economics of conflict, sport economics or labor economics. As an illustration, Table 2 provides the correspondence between the theoretical variables and possible applications of the model. Another advantage of this measure, at least for empirical studies, is that cost parameter $\lambda$ may be endogenized to capture at best the effect of fragmentation on team performance, allowing no a priori restrictions on the nature of this effect.

\section{Appendix A:}

We denote $\gamma=-\frac{\lambda}{\lambda-1}$. We have to compute $\operatorname{Lim}_{\gamma \rightarrow+\infty}\left(\sum_{p}\left(\alpha_{p}^{K}\right)^{-\gamma}\right)^{-\frac{1}{\gamma}}$. We denote $\alpha_{\min }^{K}$ the share of resources of team $K$ 's smallest group and $\left(\alpha_{\min }^{K}+\varepsilon\right)$, where $\varepsilon>0$, the resource share of the second smallest group. We can write $\sum_{p}\left(\alpha_{p}^{K}\right)^{-\gamma}=\left(\alpha_{\min }^{K}\right)^{-\gamma}\left(1+\left(1+\frac{\varepsilon}{\alpha_{\min }^{K}}\right)^{-\gamma}+\ldots\right)$. Then $\operatorname{Lim}_{\gamma \rightarrow+\infty} \sum_{p}\left(\alpha_{p}^{K}\right)^{-\gamma}=\left(\alpha_{\min }^{K}\right)^{-\gamma}$ and $\operatorname{Lim}_{\gamma \rightarrow+\infty}\left(\sum_{p}\left(\alpha_{p}^{K}\right)^{-\gamma}\right)^{-\frac{1}{\gamma}}=\operatorname{Lim}_{\gamma \rightarrow+\infty}\left(\left(\alpha_{\min }^{K}\right)^{-\gamma}\right)^{-\frac{1}{\gamma}}=\alpha_{\min }^{K}$. 


\section{Appendix B:}

We denote $\gamma=\frac{\lambda}{\lambda-1}$. We have to compute $\operatorname{Lim}_{\gamma \rightarrow+\infty}\left(\sum_{p}\left(\alpha_{p}^{K}\right)^{\gamma}\right)^{\frac{1}{\gamma}}$. We denote $\alpha_{\max }^{K}$ the share of resources of team $K$ 's largest group and $\left(\alpha_{\max }^{K}-\varepsilon\right)$, where $\varepsilon>0$, the resource share of the second largest group. We can write $\sum_{p}\left(\alpha_{p}^{K}\right)^{\gamma}=\left(\alpha_{\max }^{K}\right)^{\gamma}\left(1+\left(1-\frac{\varepsilon}{\alpha_{\max }^{K}}\right)^{\gamma}+\ldots\right)$. Then $\operatorname{Lim}_{\gamma \rightarrow+\infty} \sum_{p}\left(\alpha_{p}^{K}\right)^{\gamma}=\left(\alpha_{\max }^{K}\right)^{\gamma}$ and $\operatorname{Lim}_{\gamma \rightarrow+\infty}\left(\sum_{p}\left(\alpha_{p}^{K}\right)^{\gamma}\right)^{\frac{1}{\gamma}}=\operatorname{Lim}_{\gamma \rightarrow+\infty}\left(\left(\alpha_{\max }^{K}\right)^{\gamma}\right)^{\frac{1}{\gamma}}=\alpha_{\max }^{K}$. 


\section{References}

Akerlof, G. and Yellen, J. (1990). The fair wage-effort hypothesis and unemployment. Quarterly Journal of Economics, 105:255-283.

Depken, C. A. (2000). Wage disparity and team productivity: evidence from major league baseball. Economics letters, 67:87-92.

Dutheil de la Rochère, G., Josselin, J. M., and Rocaboy, Y. (2011). The role of aggregation technologies in the provision of supranational public goods: A reconsideration of NATO's strategies. Review of International Organizations.

Hirshleifer, J. (1983). From weakest-link to best-shot: The voluntary provision of public goods. Public Choice, 41:371-386.

Jane, W. J. (2010). Raising salary or redistributing it: A panel analysis of major league baseball. Economics letters, 107:297-299.

Jane, W. J., San, G., and Ou, Y. P. (2009). The causality between salary structures and team performance: a panel analysis in a professional baseball league. International Journal of Sport Finance, 4:136-150.

Laakso, M. and Taagepera, R. (1979). Effective number of parties: A measure with application to west europe. Comparative Political Studies, 12:3-27.

Lazear, E. and Rosen, S. (1981). Rank-order tournaments as optimum labor contracts. Journal of Political Economy, 81:841-864.

Le Maux, B., Rocaboy, Y., and Goodspeed, T. (2011). Political fragmentation, party ideology and public expenditures. Public Choice, 147:43-67.

Levine, D. (1991). Cohesiveness, productivity and wage dispersion. Journal of Economic Behavior and Organization, 15:237-255.

Padovano, F. and Venturi, L. (2001). Wars of attrition in Italian government coalitions and fiscal performance: 1984-1994. Public Choice, 109:15-54.

Sandler, T. and Hartley, K. (2001). Economics of alliances: The lessons for collective action. Journal of Economic Literature, 39:869-896.

Schaltegger, C. A. and Feld, L. P. (2009). Do large cabinets favor large governments? evidence on the fiscal commons problem for Swiss cantons. Journal of Public Economics, 93:35-47.

Skaperdas, S. (1996). Contest success functions. Economic Theory, 7:283-290.

Tullock, G. (1980). Efficient rent seeking. In Buchanan, J., Tollisson, R., and Tullock, G., editors, Toward a theory of rent seeking society, pages 97-112. College Station: TX, A\&M University Press. 